\title{
A NEW MEASURE OF THE NON-INFLATIONARY RATE OF CAPACITY UTILISATION FOR THE BRAZILIAN ECONOMY
}

\author{
Itaiguara de Oliveira Bezerra* \\ Marco Malgarini $^{\dagger}$
}

\begin{abstract}
The aim of the paper is to derive a non-inflationary rate of capacity utilisation (NIRCU) for the Brazilian economy using firm level data stemming from the IBRE/FGV survey on the manufacturing sector. In doing so, we condition the current capacity utilisation rate at the firm level on expected price changes; moreover, we also condition on the information regarding the number of shifts worked, also provided at the firm level, considered as a possible proxy of the investment gap. The NIRCU is found to perform well as an indicator of inflationary pressures in a standard Phillips-curve framework; results shows that even during the crisis the Brazilian NIRCU lies below the current level of capacity, signalling the persistence of Brazilian inflationary tensions.
\end{abstract}

Keywords: inflation; capacity utilisation; NIRCU; Phillips Curve.

JEL classification: E31, E32, E52

\section{Resumo}

O objetivo do trabalho é obter uma taxa não inflacionária de utilização da capacidade (NIRCU) à economia brasileira, utilizando microdados decorrentes da pesquisa IBRE / FGV, do setor da Indústria de Transformação. Foi condicionado a NIRCU tem relação com as mudanças de preços esperados informados pelas empresas; Além disso, também foi condicionado a informação sobre o número de turnos trabalhados, também fornecido ao nível da empresa, considerada como uma possível proxy de desinvestimento. A NIRCU apresentou bom desempenho como um indicador de pressão inflacionária no modelo de Curva de Phillips padrão; os resultados mostram que, mesmo durante a crise, a NIRCU encontra-se abaixo do nível atual de capacidade, sinalizando a persistência de tensões inflacionárias brasileiras.

Palavras-chave: inflação; capacidade utilizada; NIRCU; Curva de Phillips.

DOI: http://dx.doi .org/10.11606/1413-8050/ea 147737

\footnotetext{
* Instituto Brasileiro de Economia (IBRE/FGV). E-mail: itaiguara.bezerra@fgv.br

† Agenzia Nazionale di Valutazione del Sistema Universitario e della Ricerca (ANVUR). E-mail: malgmarco@gmail.com
} 


\section{Introduction}

The concept of non-inflationary rate of unemployment (NIRU) has been originally developed by Modigliani \& Papademos (1975) in a Phillips curve framework: according to this definition, the NIRU is the level of unemployment rate that is consistent with a stable price level. The NIRU is a short term concept, to be distinguished from the so called "natural rate" prevailing in the long run (Non Accelerating Inflation Rate of Unemployment (NAIRU). Both concepts are usually considered very useful to predict inflation and as valuable tools for the appropriate setting of monetary policies. In fact, any deviation with respect to the actual unemployment rate may be interpreted as evidence of existing inflationary (or deflationary) pressures. However, according to Staiger et al. (1997), unemployment is not the only variable that can be used to predict inflation in the short run; in particular, in a recent contribution Köberl \& Lein (2011) suggest the use of the rate of capacity utilisation in order to derive an alternative measure of inflationary pressures. In particular, Köberl \& Lein (2011), in full analogy with the NIRU, introduce the definition of a non-inflationary rate of capacity utilisation (NIRCU); the NIRCU can be used in a Phillips curve framework in order to obtain early signals of inflationary pressures. The main innovation of the Köberl-Lein paper is that their measure of the NIRCU is not derived from appropriately filtering current capacity utilisation, but rather from micro-level information based on survey data. Thus, they are able to circumvent some of the typical problems associated with data filtering. First of all, filters are particularly affected by data revision towards the end of the sample, exactly when the information is particularly relevant for policy makers; moreover, filtering methods (e.g, Kalman Filter) often rely on strict statistical assumptions (e.g. trend and cycle components being uncorrelated), lacking solid theoretical support. On the other hand, the Köberl and Lein approach relies on firm level information concerning the level of capacity utilisation and price expectations. Based on this information, they link the utilisation rate with the knowledge of whether and at what given utilisation rate a firm expects to adjust prices. More specifically, if a given firm in the data set indicates that it does not expect to adjust prices in the next period, the utilisation rate the firm currently reports can be considered to reflect the firm-specific NIRCU, defined as the rate of utilisation that is consistent with no change in prices.

Deriving the NIRCU from survey data has some distinctive advantages over more traditional methods: since survey data are usually released before the end of the month to which they refer to and are not revised, the NIRCU will have the desirable properties of being time-variant and available in advance with respect to official GDP and unemployment figures. Moreover, the NIRCU is based on precise theoretical hypothesis concerning firms pricing behaviour and does not rely on questionable statistical filtering approaches.

The method firstly introduced by Köberl and Lein was also used by Fessler et al. (2014), for the Austrian economy, and by Crosilla et al. (2014), for Italy. The goal of this paper is to adapt the method to the data extracted from the Manufacturing Survey for Brazil, developed by IBRE/FGV, with the aim of building a reliable NIRCU measure for the Brazilian economy. As far as we know, this is the first time this methodology is applied to a non-OECD developing economy, where there is much need for reliable measures of inflationary pressures. Additionally, our paper innovates on previous contributions 
in using information about the number of shifts worked as a proxy for the investment gap: if the number of shift is either greater or lower than the average value prevailing in the industry in each quarter, the NIRCU may be biased because of a positive or negative investment gap. Section 2 will introduce the FGV Manufacturing Survey for Brazil, while section 3 will derive our measure of the non-inflationary rate of capacity utilisation for the Brazilian economy. Our estimate of the Brazilian NIRCU will be used in the section 4 in order to derive a measure of inflationary pressures in a Phillips curve framework. Section 5 will comment upon the results obtained and conclude the paper.

\section{The data set}

\subsection{The Brazilian manufacturing survey}

Nowadays, business tendency surveys are conducted in a considerable number of countries ${ }^{1}$ and are considered as a very useful tool for monitoring the economic situation in real time. In fact, business survey data are usually available before the end of the period they refer to and are not revised; moreover, they contain information about variables which are important from a policy perspective but which are often unavailable from official sources, such as the level of inventories and capacity utilization. Indeed, an official measure of capacity utilization does not exist in Brazil, but information about capacity may be derived from the IBRE/FGV survey on the manufacturing sector, produced by the Brazilian Institute of Economics (IBRE) since 1966 on a quarterly basis until October of 2005, and monthly thereafter. The survey provides information on the current situation and short-term trends of the Brazilian manufacturing sector, constituting a subsidy for making business decisions in the private sphere, for economic analysis made in the academic and consulting environment and in the elaboration of economic policy by the government ${ }^{2}$.

The FGV Manufacturing Survey contains three types of questions, referred to assessments on the quarter immediately preceding the survey, assessments concerning the moment the survey is performed, and forecasts for the quarter ahead respectively. Questions are qualitative, in the sense that they ask to report about firms' opinions on the phenomena of interest rather than about quantities. Answers are usually arranged on a Likert scale, ranging from extremely positive to extremely negative. Some of the questions, however, like those regarding the level of capacity utilization and the number of shifts worked, are asked in quantitative terms. Table 1 summarizes the questionnaire, its reference period, response options and the frequency of the questions. Some of the questions are referred to the company as a whole while others target the company's specific product. Among the former there are the questions about the level of capacity utilization and questions concerning employment, purchase of raw material and components, limiting factors to the growth of production and credit conditions. The remaining questions are

\footnotetext{
${ }^{1}$ Since the early 1960s, the European Commission has been managing a program of harmonized business and consumer surveys in the EU Member States and candidate countries. OECD maintains a large database of tendency surveys from member countries and some non-member countries.

${ }^{2}$ For further information about the Brazilian Manufacturing Survey, developed by Getulio Vargas Fundation, see the following link: http: //portalibre.fgv.br/main. jsp? lumPage Id=402880811D8E34B9011D98524BB83BED
} 
asked with reference to a specific product or production line; in case the company has more than one important line of products, responses are given for each of them.

Answering firms are classified by a system of 4 sectors, 21 branches and 127 industrial areas. The four industry sectors correspond to the main industrial groupings, i.e., Consumer Goods, Capital Goods, Construction Material and Intermediate Goods. The sectoral classification is made according to the description of the characteristics of the company's products and area of operation provided by the company itself; each company is classified based on of the characteristics of its main product(s). The majority of the responses contained in the Manufacturing Survey are weighted by the company turnover at the branch level; results relative to the employment situation use the company's employment level instead, while those about foreign demand consider the value of the company's exports. Finally, branch level results are further aggregated at the industry level using information concerning branch value added.

The sample of respondents is composed of large, medium and small industrial companies intended to represent the entire population of Brazilian manufacturing firms. Most important firms in terms of revenue, personnel employed or value of industrial manufacturing production are always included in the panel; the rest of the panel is rotating each month, including however at least $30 \%$ of the total value of production in each industrial branch. Each month, about 1,400 firms are surveyed; the sample represents $40 \%$ of the total turnover and $9 \%$ of the total number of firms in the manufacturing industry. The person responsible for completing the questionnaires is identified by the company according to the specifications provided by IBRE/FGV; the person is generally an employee on the management or board level and necessarily someone with an integrated view of the various businesses and strategies of the company. Survey responses are provided mainly via internet or by phone.

\subsection{Questions about level of capacity utilisation, price expectations and number of shifts}

As stated in section 1, the aim of this paper is to derive a firm-specific NIRCU and use it as an indicator of inflationary pressures for the Brazilian economy. The IBRE/FGV manufacturing survey indeed provides relevant information for this task: in fact, it includes a question on the firm's current level of capacity utilization; moreover, the survey also comprises a question on price expectations for the next three months and another one concerning the number of shifts worked.

As far as capacity utilisation is concerned, respondent should choose between nine possible answers, arranged in brackets and ranging from $0 \%$ (production is idle) to $100 \%$ (full capacity). Subsequently, replies are quantified imputing the central value of the bracket to each firm. The information is available on a monthly basis; however, since price expectations and shifts worked are available only quarterly, the monthly series is converted into a quarterly one using the simple average of monthly observations.

As stated above, the survey also contains information about price expectations and the presence of possible capital tensions. As far as prices are concerned, firms are asked to report about the evolution of sale prices for the quarter ahead as compared to the current quarter; possible answers are that 
Table 1: Main items covered in the FGV Manufacturing Survey

\begin{tabular}{|c|c|c|c|c|}
\hline Item & $\begin{array}{l}\text { Reference period for the } \\
\text { answers }\end{array}$ & Response Options & $\begin{array}{l}\text { Frequency of } \\
\text { collection }\end{array}$ & $\begin{array}{l}\text { Company level/ } \\
\text { Product level }\end{array}$ \\
\hline Employment & Three months earlier & Increase, stable, decrease & Quarterly & Company \\
\hline Employment & Next three months & Increase, stable, decrease & Monthly & Company \\
\hline Work Shifts & Current Situation & Number of shifts & Quarterly & Product \\
\hline Level of Installed Capacity Utilization & Current Situation & $\begin{array}{l}\text { Percentage of average capacity used in } \\
\text { the reference month }\end{array}$ & Monthly & Company \\
\hline $\begin{array}{l}\text { Purchases (Raw Materials and Compo- } \\
\text { nents, by volume) }\end{array}$ & Next three months & Increase, stable, decrease & Quarterly & Company \\
\hline $\begin{array}{l}\text { Corporate costs (raw materials and la- } \\
\text { bor) }\end{array}$ & Next three months & Larger, equal, smaller & Quarterly & Company \\
\hline $\begin{array}{l}\text { Limiting factors to the expansion of pro- } \\
\text { duction in the short term }\end{array}$ & Current Situation & Seven response options & Quarterly & Company \\
\hline Credit Conditions & Current Situation & High, moderate, low & Quarterly & Company \\
\hline Delivery Time for supplier & Current Situation & Greater, equal, lower & Quarterly & Company \\
\hline Demand (domestic and foreign) & $\begin{array}{l}\text { Current } \quad \text { Situation } \\
\text { (Level) }\end{array}$ & Strong, normal or poor & Monthly & Product \\
\hline Demand (domestic and foreign) & Next three months & Increase, stable, decrease & Quarterly & \\
\hline Production & Three months earlier & Increase, stable, decrease & Quarterly & Product \\
\hline Production & Next three months & Increase, stable, decrease & Monthly & \\
\hline Stocks & $\begin{array}{l}\text { Current } \quad \text { Situation } \\
\text { (Level) }\end{array}$ & Insufficient, normal or excessive & Monthly & Product \\
\hline Practiced prices & Next three months & Greater, equal, lower & Quarterly & Product \\
\hline Business Situation & Current Situation & Good, equal or poor & Monthly & Product \\
\hline Business Situation & Next six months & Better, same or worse & Monthly & Product \\
\hline
\end{tabular}


prices are expected to be higher $(+1)$, equal $(0)$ or lower $(-1)$ than the previous quarter. The question is specific for each of the main products of the firm; however, the questionnaire also seeks information about the most relevant product in terms of sales among those comprised in the firm's basket. In this paper we will use only the information on price expectations concerning the firm's main product; Figure 1 displays the distribution of firms' replies regarding their main product in 2013.

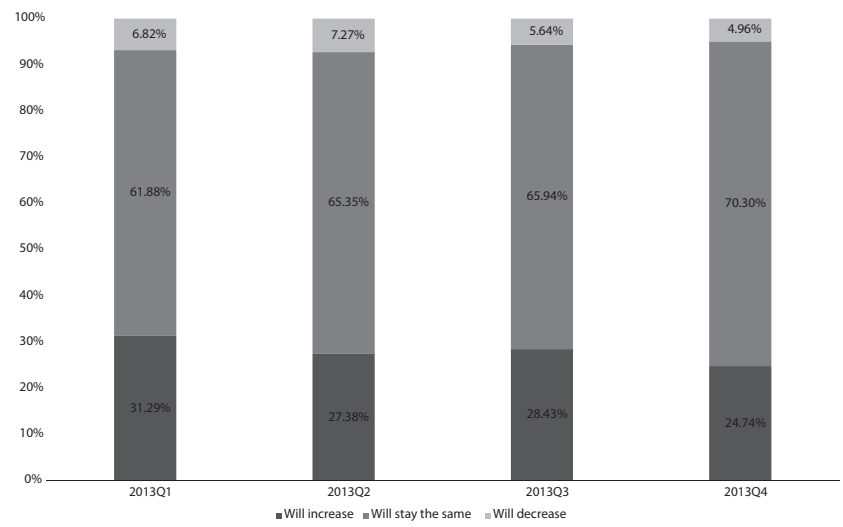

Figure 1: Prices expectations of Brazilian manufacturing firms during 2013

In the empirical literature (see Köberl \& Lein (2011), Fessler et al. (2014)), the NIRCU is usually derived also considering the information about whether capital utilisation is above or below the "norm". Indeed, according to Caballero et al. (1995), technical capacities questions may provide interesting information about the current investment gap faced by the firm: if the investment gap is positive (negative), firms may be running at high (low) capacity, even without expecting to change their prices. Then, once they have invested (dis-invested), firms may return to a more "normal" level of capacity: in these cases, firms will have declared that they are not expecting price changes, but we will observe a short-term variation in the individual firm's NIRCU, which is only attributable to the investment gap. Unfortunately, the IBRE/FGV survey lacks a direct question about technical capacities, which is comprised in the EU-Harmonised questionnaire and in the Swiss survey instead. The survey, however, does contain a question regarding the number of shifts worked in a quarter. Information on the number of shift may be used as a variable controlling for possible investment gaps. More specifically, firms have to report about the number of shifts they have employed in the quarter under consideration for each of their main productions. We consider the main production as in the case of the price expectations question, and argue that if the number of shift at the firm level is equal to the average number of shifts prevailing in the industry, then the firm is not having any pressure to invest (or disinvest) on new equipment. On the other hand, if the company is operating above (below) the average number of shifts, we assume that it is experiencing pressures to invest (disinvest) on new technical capacity. The average number of shifts in the Brazilian manufacturing industry was indeed equal to roughly 2 (2.2 to be precise) in the period considered (see Figure 2). Hence we considered that firms running their production with 2 shifts were not experiencing any 
pressure on the use of capital ${ }^{3}$.

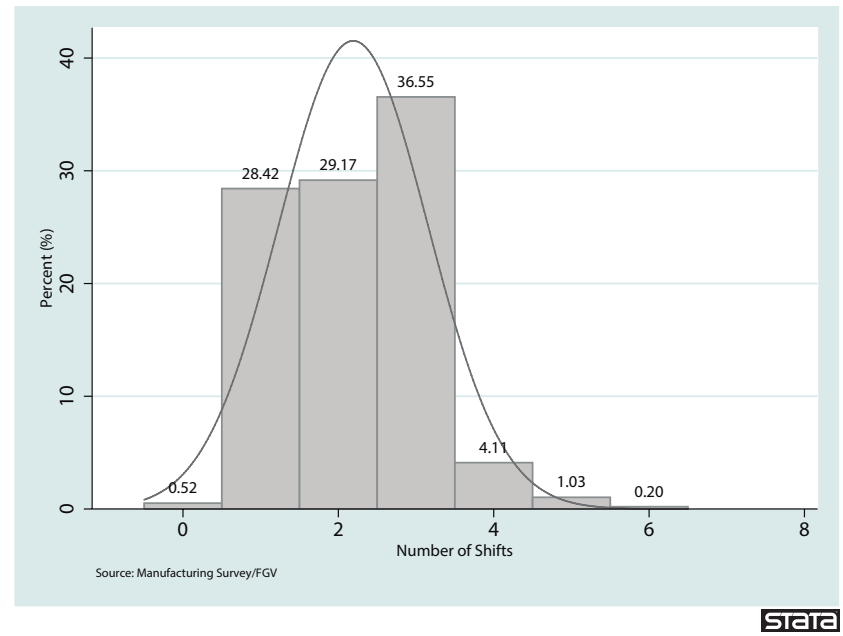

Note: We did not consider fractional and "extreme" answers (i.e. number of shifts greater than six), amounting to $0.45 \%$ of total replies

Figure 2: Distribution of the number of shifts, 2002-2013.

Using this information, Figure 3 shows the distribution of firm-level capacity rates for the entire sample and for those reporting stable prices and a number of shifts equal to the average of the sector in which the firm operates. The data considered covers the period between 2002 Q2 to 2013 Q4. In total, we have 53,573 available observations: 14,027 refer to firms operating expecting stable prices and a number of shifts equal to the average of the sector, while the number of those operating with either growing or decreasing prices and/or a number of shifts different from the average of the sector was equal to 39,546. The non-weighted average of the capacity utilisation rate for the Brazilian manufacturing sector in the period considered has been equal to $75.7 \%$, while the median value was $84.5 \%$ (showing that the distribution is rather right-skewed, as seen on the chart below); standard deviation was equal to 0.21 . Considering the whole sample (left-hand panel of Figure 3), most of the firms $(26.2 \%)$ are operating at $84.5 \%$ of their capacity, while $8.0 \%$ are operating at full capacity and only $1.9 \%$ of them are idle (i.e. are not using their productive capacity at all). Conditioning on stable prices and normal shifts, the median is still $84.5 \%$ while the average is higher than the whole sample $(77.6 \%)$; standard deviation is equal to 0.19 . Considering only the firms operating with stable prices and "normal" number of shifts, most of the firms $(29.8 \%)$ are operating at $84.5 \%$ of their capacity, with only $1.1 \%$ being idle and $7.7 \%$ at the peak of capacity.

Differences in the distribution of capacity rates among firms operating at the NIRCU and those who are not may be more adequately tested using the

\footnotetext{
${ }^{3}$ We also experimented with different measures of pressures on technical capacities, alternatively considering firms operating with stable shifts or with a number of shifts equal to the mode for the whole industry. In both cases, the distribution of capacity utilization for firms operating with stable prices and stable or normal-for-the industry shifts did not differ significantly from the one used in the paper.
} 


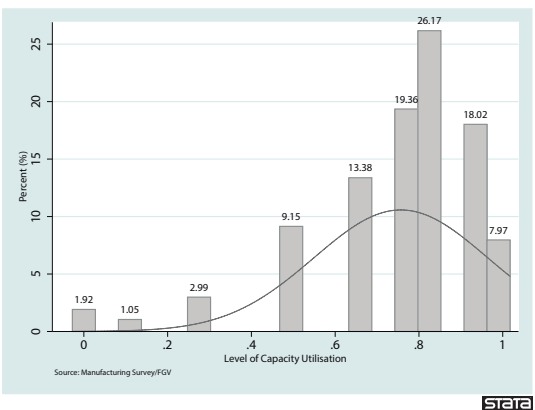

Whole sample

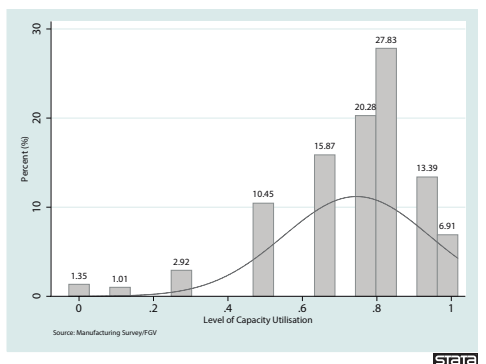

Firms operating with stable prices and average shifts

Figure 3: Distribution of capacity utilisation rates across firms conditioning on price expectations and number of shifts

two-sample Wilcoxon-Mann-Whitney test (Mann \& Whitney (1947), Wilcoxon (1945)). More specifically, the test verifies the null hypothesis that the two samples are extracted from the same distribution, against the alternative that they are drown from different pools. Running the test for the period 2002 Q2 -2013 Q4 we reject the null that the distributions are extracted from the same pool: the associated $z$-statistics is equal to 11.15 , which implies a rejection of the null at the $1 \%$ level. If we run the test for each quarter and consider the $10 \%$ significance level, we reject the null hypothesis of the two samples having the same distribution $46 \%$ of the times. Our conclusion from this part of the analysis is that indeed the two distributions are extracted from different pools, but that in more than $60 \%$ of the cases the capacity level for firms at the NIRCU is not significantly different from that of the rest of the sample. Next, we will use this definition to build up an aggregate measure of the NonInflationary Rate of Capacity Utilisation for the Brazilian economy and test whether this variable can be used as an indicator of inflationary pressures in a Phillips Curve framework.

\section{The non-inflationary rate of capacity utilisation (NIRCU) for the Brazilian economy}

On the firm level, we have defined the non-inflationary Rate of Capacity Utilisation (NIRCU) as the rate consistent with an expectation of stable prices for the next three months ${ }^{4}$. Moreover, as explained in the previous section, in order to obtain a measure of non accelerating capacity rate that is not too sensitive to the cyclical situation of the firm we also excluded from the calculation of the NIRCU firms which are experiencing positive/negative tensions on technical capacities- even if expecting to keep prices stable. Indeed, for those firms the utilisation rate may be systematically biased by a positive/negative investment gap. Hence, for each firm $i$ at time $t$ the NIRCU at the firm level is defined as:

\footnotetext{
${ }^{4}$ In both theoretical and empirical literature, the NIRCU is defined as the capacity utilisation rate consistent with current and expected stable prices. Unfortunately, information on the current prices situation is not available in the FGV manufacturing survey; however, according to Köberl \& Lein (2011), the calculation of the NIRCU is not substantially affected by conditioning either on current or expected prices, or both.
} 


$$
N I R C U_{i, t}=\left(C U_{i t} \mid \text { Price }_{i, t}^{e}=0 \cap \text { Shift } t_{i, t}=\text { SHIFT }\right)
$$

Thus the current rate of capacity utilisation for a firm, $C U_{i t}$, is consistent with the NIRCU if the firms expects prices to remain stable (i.e. Price $e_{i t}^{e}=0$ ) and if its number of shifts is equal to its average (SHIFT). We then need to aggregate the firm-level NIRCU at the industry level; in doing so, we use the same method currently used by IBRE/FGV for published data. More specifically, in a first stage we aggregate the firm-level information at the branch level using firm number of employees as weights. Let's define $N R_{i, t}=1$ if $C U_{i, t}=N I R C U_{i, t}, 0$ otherwise. Then we have that in each branch $j$ the total number of employees for firms operating at the NIRCU is equal to:

$$
\text { MaxweightNIRCU } U_{j, t}=\sum_{i} \text { employe }_{i, j} \times N R_{i, j, t}
$$

Hence, the NIRCU aggregated on the branch level is given by:

$$
\operatorname{NIRCU}_{j, t}=\sum_{i} \frac{\left(\text { employee }_{i, j, t} \times N \operatorname{NIC} U_{i, j, t}\right)}{\text { MaxweightNIRCU }_{j, t}}
$$

Once we have calculated the NIRCU for each of the 21 branches, we aggregate them at the industry level using the official branch value added as weight. Finally, to obtain a measure of the capacity utilisation gap we simply calculate the difference between the current capacity rate and that of the firms presently operating at the NIRCU:

$$
\text { Gap_C } U_{t}=C U_{t}-N I R C U_{t}
$$

Figure 4 plots the capacity rate and the NIRCU calculated using the methodology described above. In the period considered, capacity utilisation in the Brazilian manufacturing sector is on average equal to $82 \%$ showing a moderate positive trend in the period 2002-2007; it falls down to a minimum of $76 \%$ with the crisis (2009, first quarter), rapidly recovering in the period 20112013. The NIRCU lies on average slightly below the current capacity rate, being equal to $81 \%$ in the period 2002-2013; during the crisis, it falls with some delay with respect to the current rate, reaching a trough (at $78,7 \%$ ) only in the second quarter of 2012. Consequently, current capacity tends to be higher than its non-inflationary rate in the last two years, signalling the possible emergence of inflationary pressures. Indeed, according to official data, the Brazilian inflation rate remains around $6 \%$ even during the crisis, a figure that seems to be consistent with the evidence of inflationary tensions emerging from the data concerning the utilisation rate and its non-inflationary values.

As already pointed out in Köberl \& Lein (2011), the fact the NIRCU is not as smooth as its possible estimates derived from the application of some filter does not seem to conflict with the theoretical literature. There is no reason to expect the natural rate to be smooth or constant over time, since real shocks may affect its level and contribute to its volatility, especially in a highly volatile period as the one considered in this paper. Indeed, NIRCU standard deviation is equal to 2.5 , much in line with the results found in the literature for Austria and Switzerland. In the period we are considering, Brazillian GDP and manufacturing output grew on average by $3.5 \%$ and $2.4 \%$, respectively (see Figure 5); GDP and industrial production growth rates were also highly 


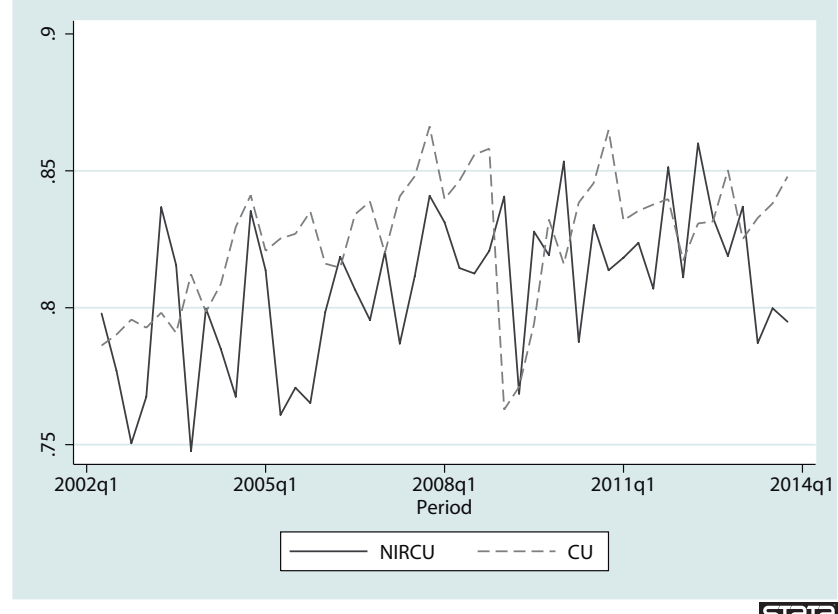

Figure 4: Capacity utilisation rates

correlated, implying that the manufacturing cycle is highly representative of the aggregate business cycle for the Brazilian economy.
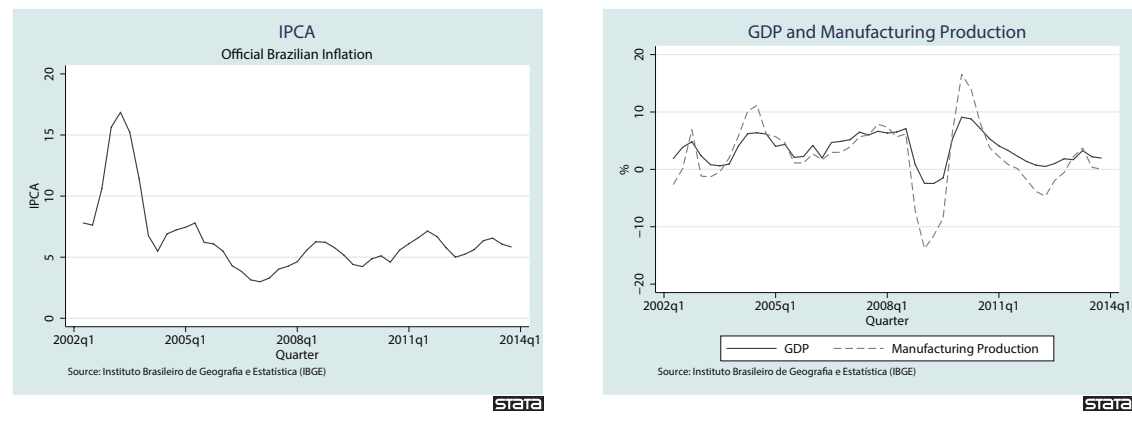

Figure 5: Macroeconomic data for Brazil

\section{The NIRCU as an indicator of inflationary pressures in a Phillips curve framework}

After having defined the NIRCU for the Brazilian economy in section 3, we now proceed to testing its usefulness for monitoring inflationary pressures. More specifically, we define an augmented Phillips curve, in order to take into consideration possible open-economy effects, including backward and forward looking components as follows:

$$
\pi_{t}=\beta_{1} \pi_{t-1}+\beta_{2} E_{t}\left\{\pi_{t+1}\right\}+\beta_{3} \Delta r_{t}+\beta_{4} g a p_{t}+\alpha
$$

In (5), $p i_{t}$ is the official Brazilian inflation rate, $E_{t}\left\{\pi_{t+1}\right\}$ is expected inflation, $r_{t}$ is the real effective exchange rate ${ }^{5}$ and gap $_{t}$ is the output gap, which

\footnotetext{
${ }^{5}$ We use the monthly real effective exchange rate, as calculated by the Bank of International Settlements; since the series result to be integrated of order 1 (I(1)), we include in the equation its quarter on quarter log-difference.
} 
is proxied in different ways. Following Gali \& Gertler (1999), and similarly to Köberl \& Lein (2011), we firstly estimate (6) with Generalised Method of Moments (GMM), assuming that expectations are rational and considering that, according to the rational expectations hypothesis, $E_{t}\left\{\pi_{t+1}\right\}$ should be incorrelated with available information dated at $t$. From this assumption, we derive the orthogonality condition that is used in the GMM estimate:

$$
E_{t}\left\{\left(\pi_{t}-\beta_{1} \pi_{t-1}-\beta_{2} \Delta r_{t}-\beta_{3} \pi_{t+1}-\beta_{4} g a p_{t}-\alpha\right) Z_{t}\right\}=0
$$

In (6), $Z_{t}$ is the vector of instruments, dated at $t$ or earlier, which is assumed to be uncorrelated with inflation expectations for the period in $t+1$. More precisely, in the estimate we use four lags each of the consumers' price inflation rate $^{6}$, the real wage inflation ${ }^{7}$, the import price index ${ }^{8}$, the quarteron-quarter change of the real effective exchange rate, the spread between the long and short term interest rates ${ }^{9}$ and the gap measure used in the regression. As a possible measure of the gap, we alternatively consider the microfounded NIRCU, the cyclical components of GDP, industrial production and the unemployment rate (with inverted sign in order to ensure a positive relationship among inflation and the gap), all extracted with the Hodrick-Prescott Filter, and a further measure derived from the IBRE/FGV survey on the manufacturing sector, simply calculated as the difference among the current level of capacity and its long time average over the period 2002-2013. Estimation results are reported in columns 1-5 of Table 2. The Hansen Test confirms that the chosen instruments are truly exogenous, and hence, their choice is appropriate. Parameters concerning past and future inflation are always significant, with the correct sign; their values are similar to what was found for the Euro Area by (Gali \& Gertler 1999) and for Switzerland, Italy and Austria, respectively, by Köberl \& Lein (2011), Crosilla et al. (2014), Fessler et al. (2014). As for the real effective exchange rate, it is statistically significant (with the expected sign) when we consider the NIRCU and the GDP and IP-based gaps, while it does not significantly affect current inflation in the specification including our cyclical measure of the capacity rate and the gap based on the unemployment rate. As for the gap based on the micro-founded NIRCU, its parameter is equal to 0.02 and it is indeed significant at the $5 \%$ level with the expected sign. Estimates of the gap parameters were equal to 0.04 for the Euro Area (Gali \& Gertler 1999) and for Austria (Fessler et al. (2014)), to 0,03 for Italy (Crosilla et al. (2014)) and to 0.09 for Switzerland (Köberl \& Lein (2011)). Hence, the coefficient we find for the Brazilian economy is in line with previous results available for developed economies.

The gap is either insignificant or with the wrong sign if we consider the cyclical component of either GDP or industrial production, or the simpler cyclical measure extracted from our survey data, as a proxy of the output gap. On the other hand, the gap measure extracted from the unemployment rate is statistically significant with the correct sign, and its parameter is higher than that of the NIRCU being equal to 0.36 . The conclusion we may derive from

\footnotetext{
${ }^{6}$ Monthly Broad Consumer Index (IPCA) developed by Brazilian Institute of Geography and Statistic (IBGE).

${ }^{7}$ Monthly Real Wage Series developed by IBGE.

${ }^{8}$ Monthy Brazilian Import Price Index developed by Foreign Trade Studies Centre Foundation (FUNCEX).

${ }^{9}$ The short term interest rate is represented by swap. The long term interest rate is represented by TJLP developed by Brazilian Central Bank (BCB).
} 
Table 2: Results of the Phillips curve estimates using GMM, 2002-2013

\begin{tabular}{lccccc}
\hline & $(1)$ & $(2)$ & $(3)$ & $(4)$ & $(5)$ \\
\hline$\pi_{t-1}$ & 0.35 & 0.32 & 0.33 & 0.37 & 0.31 \\
$\Delta r_{t}$ & $(0.035)^{* * *}$ & $(0.029)^{* * *}$ & $(0.034)^{* * *}$ & $(0.003)^{* * *}$ & $(0.025)^{* * *}$ \\
& 1.40 & 2.75 & 1.54 & 0.55 & 0.93 \\
$E_{t}\left(\pi_{t+1}\right)$ & $(0.469)^{* * *}$ & $(0.000)^{* * *}$ & $(0.545)^{* * *}$ & $(0.589)^{* * *}$ & $(0.563)^{* * *}$ \\
NIRCU & 0.67 & 0.71 & 0.70 & 0.59 & 0.73 \\
& $(0.02)^{* * *}$ & $(0.000)^{* * *}$ & $(0.027)^{* * *}$ & $(0.027)^{* * *}$ & $(0.024)^{* * *}$ \\
gap GDP & 0.02 & & & & \\
gap IP & $(0.007)^{* * *}$ & & & & \\
& & -0.03 & & & \\
gap UNEM & & $(0.017)$ & -0.02 & & \\
& & & $(0.005)^{* * *}$ & & \\
cycle LCU & & & & 0.36 & \\
& & & & & $-0.118)^{* * *}$ \\
Constant & -0.26 & -0.24 & -0.23 & 0.21 & -0.26 \\
& $(0.157)$ & $(0.132)^{* *}$ & $(0.151)$ & $(0.164)$ & $(0.125)$ \\
Observations & 39 & 39 & 39 & 39 & 39 \\
Hansen J-stat & 9.28 & 9.39 & 8.596 & 10.04 & 9.27 \\
& $(0.96)$ & $(0.97)$ & $(0.98)$ & $(0.95)$ & $(0.97)$ \\
\hline
\end{tabular}

Standard error in parenthesis. ${ }^{\star} \mathrm{p}<0.10 ;{ }^{* \star} \mathrm{p}<0.05 ;{ }^{* \star} \mathrm{p}<0.01$.

these results is that the micro-founded NIRCU is a good indicator of inflationary pressures for the Brazilian economy. Indeed, its reliability in a Phillips Curve framework is higher than what can be obtained using the cyclical component of the GDP or industrial production, or the simple difference among capacity and its long-term trend, and is in line with that obtainable using the unemployment rate.

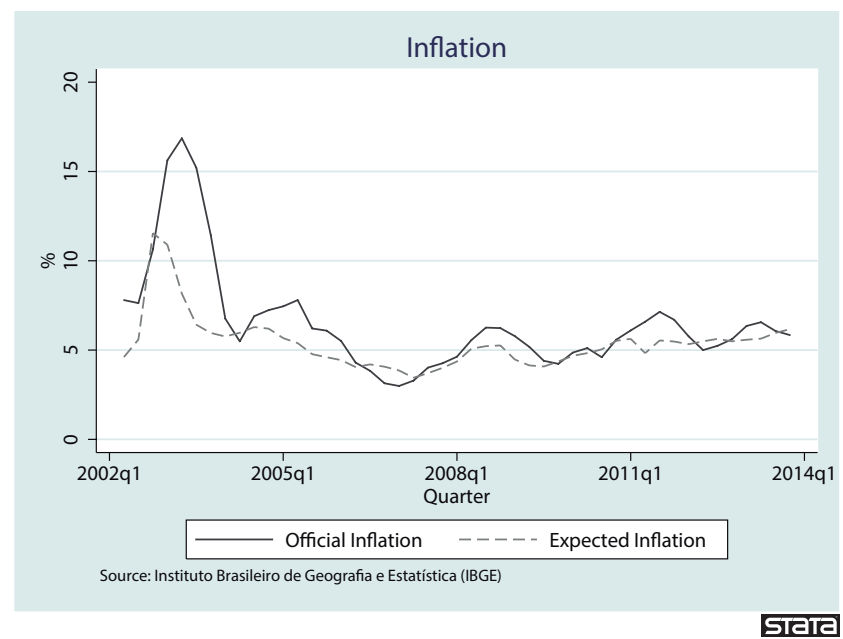

Figure 6: Prices expectations of Brazilian manufacturing firms during 2013

As a robustness check with respect to the results provided in Table 2, we reestimate equation (6) using a direct measure of inflation expectations derived from a survey on professional forecasters performed by the Brazilian Central 
Bank $(\mathrm{BCB})^{10}$. The BCB survey among experts is released on a daily basis and aggregated quarterly; the series may be considered as a good 1-quarter ahead leading indicator for Brazilian official inflation (see fig. 6) ${ }^{11}$. Indeed, the use of GMM has been criticised (Dufour et al. (2006)) on the grounds of possible weakness in resulting inference; moreover, Köberl \& Lein (2011) have shown that OLS estimates based on survey data perform as well as the GMM approach to test for the contribution of the NIRCU in the Phillips curve framework. The use of a direct measure of expectations allow us to estimate the equation with OLS, using Newey-West corrected standard errors (see among others Henzel \& Wollmershäuser (2008), for an application relative to European countries). Estimation results are reported in Table 3. As in Table 2, columns 1-5 present the results obtained using different proxies for the output gap: the only case in which indeed the gap is a statistically significant (albeit only at the $10 \%$ level) explicative variable for Brazilian inflation is when we use our measure of the NIRCU to approximate it. The estimated parameter is equal to 0.05 a figure in line with results emerging for Austria (0.04), but lower than that found in Switzerland (0.09). The other measures of the gap are not significant, not even at the $10 \%$ level. The estimated coefficients for lagged inflation are comprised between 0.60 and 0.64 depending on the gap proxy used in the estimation a finding broadly in line with respect to previous estimates. Expected inflation coefficients are close to one, showing that actual inflation is sensitive to expectations prevailing in the market, a finding that is in line with previous results for the Brazilian economy (Machado \& Portugal (2014)).

\section{Conclusions}

In this paper, we apply a new method firstly introduced by Köberl \& Lein (2011) to derive a Non-inflationary Rate of Capacity Utilisation (NIRCU) for the Brazilian economy. As far as we know, this is the first time such a method has been applied to a developing country, where having a reliable indicator for inflationary pressures at hand is particularly policy-relevant. In doing so, we use firm-level information on capacity utilisation, inflation expectations and shifts worked derived from the IBRE/FGV survey on the manufacturing sector. Our output gap measure is positive on average in the period 20022013 , i.e. the NIRCU lies on average below the current level of capacity; the same evidence is found even for the most recent period, when the Brazilian economy slowed down with respect to the higher growth rates registered in the last decade. In other words, our indicator signals the persistence of inflationary tensions characterising the Brazilian economy, tensions which seem to be confirmed looking at official data, since inflation remains close to $6 \%$ on average also in the aftermath of the crisis. As a formal check of the ability of our indicator to gauge the existence of inflationary tensions, we estimate a new Keynesian Phillips curve considering both GMM estimation and a direct

\footnotetext{
${ }^{10}$ Brazilian Central Bank (BCB) manages a daily survey among economists from 120 institutions (banks, funds, consulting companies). The survey asks them about their expectations about inflation and macroeconomics variables for one-year ahead horizon. In the paper, we consider the median value of each day, and take its quarterly average to obtain quarterly inflation expectations.

${ }^{11}$ The cross correlation function among actual and expected inflation peaks at lag 1 , the coefficient being equal to 0,90 .
} 
Table 3: Results of the Phillips curve estimates using OLS, 2002-2013

\begin{tabular}{|c|c|c|c|c|c|}
\hline & (1) & (2) & (3) & (4) & (5) \\
\hline$\pi_{t-1}$ & $\begin{array}{c}0.60 \\
(0.073)^{* * *}\end{array}$ & $\begin{array}{c}0.64 \\
(0.080)^{* * *}\end{array}$ & $\begin{array}{c}0.62 \\
(0.080)^{* * *}\end{array}$ & $\begin{array}{c}0.66 \\
(0.074)^{* * *}\end{array}$ & $\begin{array}{c}0.62 \\
(0.070)^{* * *}\end{array}$ \\
\hline$\Delta r_{t}$ & $\begin{array}{c}4.19 \\
(2.041)^{* *}\end{array}$ & $\begin{array}{c}4.28 \\
(2.290)^{*}\end{array}$ & $\begin{array}{c}4.07 \\
(2.346)^{*}\end{array}$ & $\begin{array}{c}4.47 \\
(2.083)^{* * *}\end{array}$ & $\begin{array}{c}4.30 \\
(2.331)^{*}\end{array}$ \\
\hline$E_{t}\left(\pi_{t+1}\right)$ & $\begin{array}{c}0.95 \\
(0.096)^{* * *}\end{array}$ & $\begin{array}{c}0.92 \\
(0.109)^{* * *}\end{array}$ & $\begin{array}{c}0.95 \\
(0.109)^{* * *}\end{array}$ & $\begin{array}{c}0.87 \\
(0.102)^{* * *}\end{array}$ & $\begin{array}{c}0.94 \\
(0.099)^{* * *}\end{array}$ \\
\hline NIRCU & $\begin{array}{l}0.05 \\
(0.03)^{*}\end{array}$ & & & & \\
\hline gap GDP & & $\begin{array}{c}0.12 \\
(0.077)\end{array}$ & & & \\
\hline gap IP & & & $\begin{array}{c}0.01 \\
(0.036)^{* * *}\end{array}$ & & \\
\hline gap UNEM & & & & $\begin{array}{c}0.54 \\
(0.361)\end{array}$ & \\
\hline cycle LCU & & & & & $\begin{array}{c}0.05 \\
(0.039)\end{array}$ \\
\hline Constant & $\begin{array}{l}-2.82 \\
(0.470)^{* * * *}\end{array}$ & $\begin{array}{l}-2.68 \\
(0.537)^{* * *}\end{array}$ & $\begin{array}{l}-2.66 \\
(0.522)^{* * *}\end{array}$ & $\begin{array}{l}-2.54 \\
(0.581)^{* * * *}\end{array}$ & $\begin{array}{l}-2.63 \\
(0.537)^{* * *}\end{array}$ \\
\hline Observations & 47 & 47 & 47 & 47 & 47 \\
\hline F-stat & 137.05 & 136.092 & 130.96 & 143.58 & 132.39 \\
\hline$R^{2}$ & 0.92 & 0.92 & 0.92 & 0.93 & 0.92 \\
\hline
\end{tabular}

measure of inflation expectations produced by the Brazilian Central Bank. According to the estimates, our measure of the output gap performs better than other more traditional measures as a predictor of inflation. Moreover, with respect to those other measures, the micro-founded NIRCU has several distinct advantages: first of all, it relies directly on firm-level information, without the need of using statistical filtering procedures which are usually considered as particularly weak especially when it counts most, i.e. towards the end of the sample. Secondly, it is theoretically well founded on the idea of the natural rate. Finally, it is available in real time and it is not revised with subsequent releases of the data. Hence, the NIRCU may be considered - also in an emerging country like Brazil - as a potentially very valuable new tool for anticipating inflation trends and for the correct setting of monetary policies.

\section{Acknowledgment}

The authors wish to thank Aloisio Campelo Jr. for his suggestions and encouragement throughout the preparation of the paper. We also gratefully acknowledge the suggestions of the anonymous referees, the editor and of the participants to the 32nd CIRET Conference, HangZhou, China, October 2014. And the authors thank the financial support from Instituto Brasileiro de Economia (IBRE/FGV) as well. The usual disclaimer applies. The views expressed in the paper are those of the authors and do not involve the responsibility of the institutions they belong.

\section{Bibliography}

Caballero, R., Engel, E. \& Haltiwanger, J. (1995), 'Plant-level adjustment and aggregate investment dynamics', Brookings Papers on Economic Activity 26(2), 1-54. 
URL: http://EconPapers.repec.org/RePEc:bin:bpeajo:v:26:y:1995:i:1995-2:p:154

Crosilla, L., Leproux, S. \& Malgarini, M. (2014), The impact of the crisis on italian industrial capacity: an assessment based on the istat manufacturing survey, MPRA Paper 67531, University Library of Munich, Germany.

URL: https://ideas.repec.org/p/pra/mprapa/67531.html

Dufour, J.-M., Khalaf, L. \& Kichian, M. (2006), 'Inflation dynamics and the new keynesian phillips curve: An identification robust econometric analysis', Journal of Economic Dynamics and Control 30(9-10), 1707 - 1727. Computing in economics and finance10th Annual Conference on Computing in Economics and Finance.

URL: http://www.sciencedirect.com/science/article/pii/S0165188906000595

Fessler, P., Rumler, F. \& Schwarz, G. (2014), 'A micro-based non-inflationary rate of capacity utilisation as a measure of inflationary pressure: evidence for austria', Empirica 41(1), 23-36.

Gali, J. \& Gertler, M. (1999), 'Inflation dynamics: A structural econometric analysis', Journal of Monetary Economics 44(2), 195-222.

Henzel, S. \& Wollmershäuser, T. (2008), 'The New Keynesian Phillips curve and the role of expectations: Evidence from the CESifo World Economic Survey', Economic Modelling 25(5), 811-832.

Köberl, E. M. \& Lein, S. M. (2011), 'The nircu and the phillips curve: an approach based on micro data', The Canadian Journal of Economics / Revue canadienne d'Economique 44(2), 673-694.

URL: http://www.jstor.org/stable/41336379

Machado, V. d. G. \& Portugal, M. S. (2014), Phillips curve in Brazil: an unobserved components approach, Working Papers Series 354, Central Bank of Brazil, Research Department.

URL: https://ideas.repec.org/p/bcb/wpaper/354.html

Mann, H. B. \& Whitney, D. R. (1947), 'On a test of whether one of two random variables is stochastically larger than the other', Ann. Math. Statist. 18(1), 50-60.

URL: $h t t p: / / d x$.doi.org/10.1214/aoms/1177730491

Modigliani, F. \& Papademos, L. (1975), 'Targets for Monetary Policy in the Coming Year', Brookings Papers on Economic Activity 6(1), 141-166.

URL: https://ideas.repec.org/a/bin/bpeajo/v6y1975i1975-1p141-166.html

Staiger, D., Stock, J. H. \& Watson, M. W. (1997), 'The NAIRU, Unemployment and Monetary Policy', Journal of Economic Perspectives 11(1), 33-49.

Wilcoxon, F. (1945), 'Individual comparisons by ranking methods', Biometrics Bulletin 1(6), 80-83.

URL: $h t t p: / / w w w . j s t o r . o r g / s t a b l e / 3001968$ 